\title{
AC 2011-889: INCORPORATING SOCIAL AND ETHICAL IMPLICATIONS OF NANOTECHNOLOGY IN THE ENGINEERING AND TECHNOLOGY CURRICULA
}

\section{Ahmed S. Khan, DeVry University,Addison, Illinois}

Dr. AHMED S. KHAN is a senior Professor in the College of Engineering and Information Sciences, DeVry University, Addison, Illinois. He received his M.Sc (applied physics) from University of Karachi, an MSEE from Michigan Technological University, an MBA from Keller Graduate School of Management., and his Ph.D. from Colorado State University. His research interests are in the areas of Fiber Optic Communications, Faculty Development, Nanotechnology, Application of Telecommunications Technologies in Distance Education, and impact of Technology on Society. He teaches Wireless Engineering, Network Engineering, Fiber Optic Communications, Technology and Society, and Project Management. He also advises students on their senior design projects. He is the author of "The Telecommunications Fact Book, 2E" and co-author of "Technology and Society: Crossroads to the 21st Century," "Technology and Society: A Bridge to the 21st Century," and "Technology and Society: Issues for the 21st Century and Beyond." He is a member of ASEE, and a senior member of IEEE.

\section{Aram Agajanian, DeVry University, Chicago}

Dr. Aram Agajanian is a senior professor at DeVry University in Chicago. He holds a B.S. in Electrical Engineering from University of Rochester, a M.S. in Electrical Engineering from Syracuse University, a Ph.D. in Educational Leadership from Colorado State University. He teaches electronics and computer technology courses including LAN and WAN. He has 10 years of industrial experience in electrical engineering; his research interests include understanding the issues that affect enrollment and retention of female students in science, math, engineering and technology (SMET) and help increase the female student population in SMET fields. He is also interested in teaching methods such as brain-based teaching, constructivism, team teaching and active learning that might improve the quality of engineering education. 


\title{
Incorporating Social and Ethical Implications of Nanotechnology in the Engineering and Technology Curricula
}

\begin{abstract}
The projected impact of nanotechnology has been touted as a second industrial revolution -- not the third, fourth, or fifth, because despite similar predictions for technologies such as computers and robotics, nothing has yet eclipsed the first. ${ }^{1}$

Society is at the threshold of a revolution that will transform the ways in which materials and products are created. How will this revolution develop? The opportunities that will develop in the future will depend significantly upon the ways in which a number of challenges are met. As we design systems on a nanoscale, we develop the capability to redesign the structure of all materials -- natural and synthetic along with rethinking the new possibilities of the reconstruction of any and all materials. Such a change in our design power represents tremendous social and ethical questions. In order to enable our future leadership to make decisions for sustainable economic nanotechnological development, it is imperative that we educate all nanotechnology stakeholders about the short-term and long-term benefits, limitations and risks of nanotechnology. The social implications of nanotechnology encompass so many fundamental areas such as ethics, privacy, environment, and security. ${ }^{2}$

This paper presents an overview of new and emerging nanotechnologies and their societal and ethical implications to address $21^{\text {st }}$ Century challenges and issues. The discussion includes a range of different types of nanotechnologies and their potential social and ethical implications on society. The paper also highlights the approach used to teach Science, Technology and Society (STS) course at DeVry University, Addison, IL.
\end{abstract}

\section{Introduction}

The nanoscale is not just another jump towards miniaturization, but a qualitatively new scale. The new behavior is dominated by quantum mechanics, material confinement in small structures, large interfacial volume fraction, and other unique properties, phenomena and processes. Many current theories of matter at the microscale will be inadequate to describe the new phenomena at the nanoscale. ${ }^{3}$

As the global economy continues to be transformed by new technology, an intense competition will grow for intellectual capital and intellectual property. Technology will continue to drive the global and domestic GDP. ${ }^{4}$ The National Science Foundation predicts that the global marketplace 
for goods and services using nanotechnologies will grow to $\$ 1$ trillion by 2015 and employ 2 million workers. It is estimated that by 2015 nanotechnology will be a $\$ 3$ trillion-a-year global industry. In 1997 the investment in nanotechnology stood at $\$ 430$ million to more than $\$ 9$ billion in 2004. There more than 800 products in the market place that have been developed using nanotechnology. 5

\section{Nanotechnology and Education and Workforce of Future}

It is estimated that by 2015 nanotechnology will be a \$3 trillion-a-year global industry. In 1997 the investment in nanotechnology stood at $\$ 430$ million, rising to more than $\$ 9$ billion in 2004. Presently more than 800 products have been developed using nanotechnology.

The development of nanotechnology requires multidisciplinary teams of highly trained researchers with backgrounds in biology, medicine, mathematics, physics, chemistry, material science, electrical engineering, and mechanical engineering. For innovative advances in nanotechnology, the key is researchers with expertise in multiple subsets of these disciplines since so many implications and fields are linked to a nano "micro-revolution." 6

\section{Social Implications of Nanotechnology}

The projected impact of nanotechnology has been touted as a second industrial revolution -- not the third, fourth, or fifth, because despite similar predictions for technologies such as computers and robotics, nothing has yet eclipsed the first. ${ }^{7}$

Society is at the threshold of a new revolution that will change the ways in which materials and products are manufactured. How will this revolution unfold? The opportunities that will develop in the future will depend primarily upon the ways in which a number of challenges are met. As we design systems at atomic scale, we develop the capability to redesign the structure of all materials -- natural and synthetic along with rethinking the new possibilities of the reconstruction of any and all materials. Such a change in our design power represents tremendous social and ethical questions. Our future leadership and stakeholders ought to be trained in the social and ethical implications of technology so that they can envision the short-term and long-term risks and benefits of nanotechnology, and can deal with its unintended consequences.

Nanotechnology, like its predecessor technologies, will have an impact on all areas. For example, in healthcare it is very likely that nanotechnology in the area of medicine will include automated diagnosis. This in turn will translate into fewer patients requiring physical evaluation, less time needed to make a diagnosis, less human error and wider access to health care facilities. And with nanomedicines if the average life span of humans increases, it will create a large portion of elderly persons requiring medical attention, resulting in increased health costs. ${ }^{8}$

It is essential for the nanotechnology stakeholders to strive to achieve four social objectives (1) developing a strong understanding of local and global forces and issues which affect people and societies, (2) guiding local/global societies to appropriate uses of technology, (3) alerting societies to technological risks and failures, and (4) developing informed and ethical personal decision-making and leadership to solve problems in a technological world. ${ }^{4}$ 
Advances in nanotechnology also present numerous challenges and risks in health and environmental areas. Nanotechnology risk assessment methods and protocols need to be developed and implement by the regulatory bodies. Eric Drexler, author of Engines of Creation has identified four challenges in dealing with the development, impact and effects of Nanotechnology on society. ${ }^{9}$

(1) The Challenge of Technological Development (control over the structure of matter)

(2) The Challenge of Technological Foresight (sense of the lower bounds of the future possibilities)

(3) The Challenge of Credibility and Understanding (clearer understanding of what these technological possibilities)

(4) The Challenge of Formulating Public Policy (formulating polices based on understanding)

Table 1 lists nanotechnology application areas and potential benefits and risks.

Table 1. Nanotechnology: Benefits and Risks

\begin{tabular}{|c|c|}
\hline Nanotechnology Application Area & Potential Benefits \\
\hline Ecology & $\begin{array}{l}\text { Nanoparticles have extremely high surface } \\
\text { areas compared to their volume; this } \\
\text { characteristic makes them ideal for the } \\
\text { fabrication of: } \\
\text { - New catalysts } \\
\text { - Heat reflection layers } \\
\text { - Aerogels for transparent damping } \\
\text { - layers in solar architectures } \\
\text { - Super thermal insulators } \\
\text { Transparent layers showing } \\
\text { resistance against wear and abrasion } \\
\text { or anti-damping properties }\end{array}$ \\
\hline Energy & $\begin{array}{l}\text { Nanodevices will allow cleaner energy } \\
\text { production and improved storage. } \\
\text { - } \quad \text { Small, compressed particles enable } \\
\text { new photo-voltaic cells, with } \\
\text { simpler structure than conventional } \\
\text { ones } \\
\text { - } \begin{array}{l}\text { Plastics to be used as the electrode } \\
\text { materials }\end{array}\end{array}$ \\
\hline Dematerialization & $\begin{array}{l}\text { Nanocrystalline particles, with a } \\
\text { mono disperse size distribution, to } \\
\text { be formed into macroscopic parts } \\
\text { with higher strength and resistance } \\
\text { against mechanical and thermal } \\
\text { load, despite the smaller amounts of } \\
\text { material required. These parts can }\end{array}$ \\
\hline
\end{tabular}




\begin{tabular}{|c|c|}
\hline & $\begin{array}{l}\text { be hard and flexible in a unit and } \\
\text { can replace scarce materials. } \\
\text { New processing techniques using } \\
\text { remarkably lower temperatures, } \\
\text { offer possibilities for minimizing } \\
\text { energy consumption during } \\
\text { component fabrication. }\end{array}$ \\
\hline Health & $\begin{array}{l}\text { More effective pharmaceuticals } \\
\text { with reduced secondary effects due } \\
\text { to improved basic understanding of } \\
\text { the efficacy of natural human } \\
\text { substances like insulin or hormones. } \\
\text { - New form of localized drug } \\
\text { delivery systems based on the } \\
\text { potential of water soluble, } \\
\text { pharmacologically active } \\
\text { substances when attached to } \\
\text { nanometer size particles } \\
\text { - External control and incorporation } \\
\text { of target information by } \\
\text { incorporating magnetic particles or } \\
\text { antibodies into the drug delivery } \\
\text { system }\end{array}$ \\
\hline Electronics/Telecommunications & $\begin{array}{l}\text { Logical building blocks, for digital } \\
\text { electronics, based on particles or } \\
\text { molecules. } \\
\text { - Nano-sized electronic data storage } \\
\text { and processing systems }\end{array}$ \\
\hline Nanotechnology Application Area & Potential Risks/Detrimental Effects \\
\hline Genetics/medicine/healthcare & $\begin{array}{l}\text { - Artifacts based on Nanotechnology } \\
\text { incorporate genetic material or have } \\
\text { genetic modification or repair as an } \\
\text { objective } \\
\text { - If the artifact incorporates some } \\
\text { kind of computing and sensing } \\
\text { element, say for the controlled } \\
\text { delivery of a drug, additional risks } \\
\text { arise for the patient if these } \\
\text { elements should malfunction. } \\
\text { - Invasion of privacy and of human } \\
\text { body through the planting and } \\
\text { implanting of computing cum } \\
\text { communication devices without the } \\
\text { knowledge of those affected } \\
\text { knowing this has been done. } \\
\text { - Security and safety of the person, }\end{array}$ \\
\hline
\end{tabular}




\begin{tabular}{|c|c|}
\hline & $\begin{array}{l}\text { since it will be very difficult } \\
\text { initially to detect the presence of } \\
\text { nano-sized artifacts that are capable } \\
\text { of breaching security and harming } \\
\text { the individual. } \\
\text { - In warfare, controlled distribution } \\
\text { of biological and nerve agents may } \\
\text { become feasible. }\end{array}$ \\
\hline Materials/composites & $\begin{array}{l}\text { - The general problem with } \\
\text { composite materials is that they are } \\
\text { more difficult to recycle and } \\
\text { consume more energy during } \\
\text { recycling than pure materials. } \\
\text { - Wide-scale introduction of } \\
\text { composite materials can increase } \\
\text { environmental problems }\end{array}$ \\
\hline $\begin{array}{l}\text { Self-assembling and self-replicating nature } \\
\text { of nanotechnological processes }\end{array}$ & $\begin{array}{l}\text { In manufacturing area, many processes will } \\
\text { need to be redesigned embodying new } \\
\text { principles, particularly relating to } \\
\text { containment of active or waste products. }\end{array}$ \\
\hline \multicolumn{2}{|c|}{$\begin{array}{l}\text { Source: Meyer, M. (2001). Socio-Economic Research and Nanoscale Science and } \\
\text { Technology, Societal Implications of Nanoscience and Nanotechnology, National } \\
\text { Science Foundation. pp. 224-225, Available online: } \\
\text { http://www.wtec.org/loyola/nano/NSET.Societal.Implications/ }\end{array}$} \\
\hline
\end{tabular}

IV. Technology, Society and Culture Course: Objectives and Methodologies

Students at DeVry University are given the challenge and opportunity to guide and direct their technological knowledge into responsible awareness and choices for local/global solutions of problems and $21^{\text {st }}$ Century urgent issues. All DeVry students must pass a senior-level interdisciplinary capstone Humanities course entitled "Technology, Society and Culture (HUMN432)." This course challenges students to realistically assess technological implications within the world stage and to bridge the gap between the developed world and the developing worlds. The course falls into the inter-disciplinary STS classification (a field known as Science, Technology and Society whose main focus is to explore the influences of technologies on society and the relationships between societies and technologies). The course emphasizes an integration of all their previous studies at DeVry in addition to professional group work, research, research presentations and technical reports, communication, critical thinking and analysis, solutions and applications of the moral and ethical dilemmas the use of technology sometimes presents. The course also identifies conditions that have promoted technological development and assesses the social, political, historic, environmental, ethical, cultural and economic effects of current technology and what technology might hold for the future on the local, national and international fronts. The challenges of this course include the interdisciplinary dimensions as well as the multi-cultural perspectives that are needed along with the dynamic of constantly changing 
current and relevant issues associated in the news which revolve around the ethical and responsible use of technology.

This course is very relevant in not only the interdisciplinary knowledge it encourages, but especially for our students who as future engineers cannot be blind to social issues and the implications of the technologies that they promote and use. Our future engineers must guide society to the appropriate uses of technology, alert society to technological failures, and provide a vision to society in helping to solve societal problems that are related to technology. Using Nanotechnology as an urgent example for responsible decision making, a number of teaching and learning tools are used including: cultural field studies, case studies, modeling, and flow charts. Such approaches promote not only concept and practical awareness but also lead to constructivist understanding of macro and micro problems of present and future technologies and issues. $^{4,6}$

In HUMN-432 course students are first given an introduction to the nanotechnology through lectures with the help of scenarios, case studies and web exercises, and then they are required to work in teams to explore the ramifications of by writing a research paper and presenting their findings in form of an oral presentation on one of the following topics:

- Nanotechnology Ethical Implications

- Nanotechnology Social Implications

- Nanotechnology and Healthcare and Medicine

- Nanotechnology and Consumer Electronics

- Nanotechnology and Biotechnology

- Nanotechnology and Ecology

- Nanotechnology and Military Applications

- Nanotechnology: International Perspective

- Future implications of Nanotechnology

Students learning and performance outcomes are evaluated with the help of an assessment tool that gauges student competencies with respect to the following General Education program goals:

1. Communicate clearly with particular audiences for particular purposes.

2. Work collaboratively to help achieve individual and group goals.

3. Apply critical thinking skills in learning, conducting applied research, and defining and solving problems.

4. Develop tolerance of ambiguity and mature judgment in exploring intellectual issues.

5. Build on intellectual curiosity with fundamental concepts and methods of inquiry from the sciences, social sciences, and humanities to support life-long learning.

6. Apply mathematical principles and concepts to problem solving and logical reasoning.

7. Use study and direct experience of the humanities and social sciences to develop a clear perspective on the breadth and diversity, as well as the commonality, of human experience.

8. Connect general education to the ethical dimensions of issues and to responsible, thoughtful citizenship in a democratic society. 
To gauge the students' understanding of nanotechnology and their perceptions about its impact on society, a survey is also conducted at the end of the course using a questionnaire (see Appendix A). The results of the most recent (Fall 2010) student survey are exhibited in appendix B.

\section{Conclusion}

The paper presented an overview of new and emerging Nanotechnologies and their potential benefits and risks. It also discussed various nanotechnology areas and applications that should be incorporated into STS courses to help students develop an understanding of societal and ethical implications of nanotechnology. Furthermore it also presented the description of STS course methodologies at DeVry University, and students' perceptions of their understanding of the impact of nanotechnology on society.

References

1. Hall, Storrs. 2005. Nanofuture: What's next for Nanotechnology. 9. Amherst, New York: Prometheus Book

2. Privacy implications of Nanotechnology, Electronic Privacy Information Center, Viewed April 28, 2009. http://www.epic.org/privacy/nano/

3. Roco, Mihail C. and Bainbridge, William. 2001. Editor, The Societal Implications of Nanoscience and Nanotechnology, NSET Workshop Report. National Science Foundation. Available Online: http://www.wtec.org/loyola/nano/societalimpact/nanosi.pdf

4. Khan, Ahmed S. 2006. Examining the Impact of Nanotechnologies for Science, Technology and Society (STS) Students. 2006 ASEE Conference Proceedings. Chicago. IL.

5. Ehrmann, R. (2008). Hands-on nanofabrication workshop for educators, Center for Nanotechnology Education and Utilization, Penn State University, Philadelphia, PA, Tuesday, December 2-4.

6. Khan, Ahmed S. (2010). An Overview of Nanotechnology and Nanoscience. Handbook of Nanotechnology for Telecommunications, pp 1-22. CRC Press.

7. Hall, Storrs. 2005. Nanofuture: What's next for Nanotechnology. 9. Amherst, New York: Prometheus Book.

8. Moore, Fiona (2004) Implications of Nanotechnology Applications: Using Genetics as a Lesson. Health Law Review, Volume 10, and Number 3.

9. Drexler, Eric (1989). The Challenge of Nanotechnology, viewed April 28, 2009.http://www.halcyon.com/nanojbl/NanoConProc/nanocon1.html\#anchor528648 


\section{Appendix A}

\section{Nanotechnology Survey}

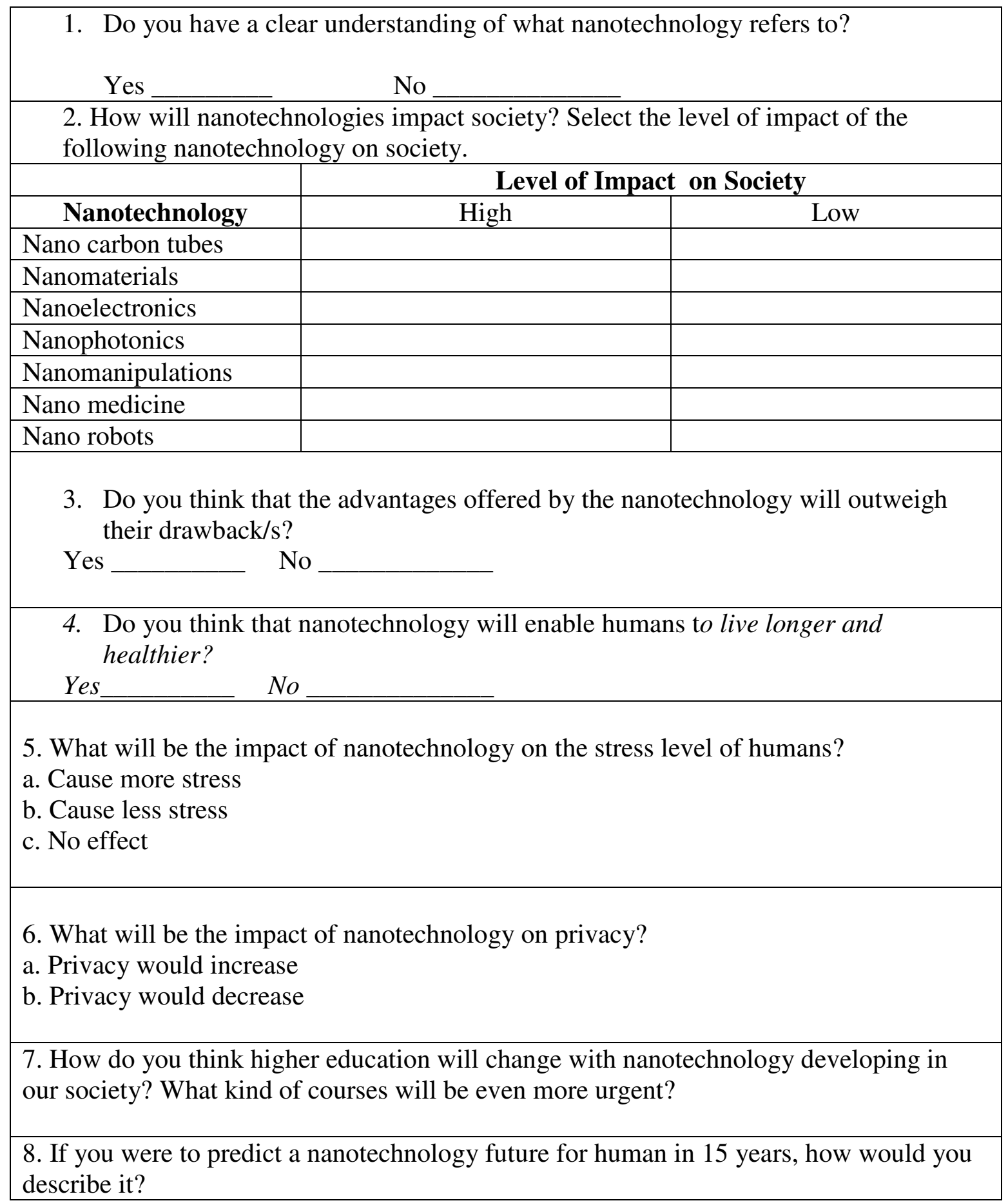




\section{Appendix B \\ Survey Results}

To gauge the students' understanding of nanotechnology and their perceptions about its impact on society, a survey is also conducted at the end of the course using a questionnaire (see

Appendix A). The results of the most recent (Fall 2010) student survey $(\mathrm{N}=127)$ are as follows:

Question 1. Do you have a clear understanding of what nanotechnology refers to?

- More than $82 \%$ respondents agreed that they have a clear understanding of nanotechnology.

Question 2. How will nanotechnology impact society? Select the level of following nanotechnology on society?

- There was a high level of agreement (95\%) among respondents that nanotubes, nanomaterials, nanoelectronics, nanomanipulations, nanomedicine and nanorobots will have a high level of impact on society.

Question 3.Do you think that the advantages offered by the nanotechnologies will outweigh their drawbacks?

- $82 \%$ respondents agreed that the advantages offered by nanotechnology will outweigh their drawbacks.

Question 4. Do you think that nanotechnology will enable humans to live longer and healthier?

- $88 \%$ respondents agreed.

Question 5. How will nanotechnology increase or decrease the stress level of humans?

- $82 \%$ of respondents believed that nanotechnology will increase stress level of humans.

Question 6. What will be the impact of nanotechnology on privacy?

- $92 \%$ of the respondents think that nanotechnology will reduce privacy.

Question 7. How do you think higher education will change with nanotechnology developing in our society? What kind of courses will be even more urgent?

Most of the students said that there will be an increase in nanotechnology courses and that there will be more international competition and demand for such courses at a high knowledge level. Some of the selected responses are:

- "Higher education will have to focus more on nanotechnology."

- "All courses in social sciences, engineering and technology areas need to focus on Nontechnology."

- "Academia needs to focus on social and ethical implications of this invisible technology!" 
Question 8. If you were to predict a nanotechnology future for humans in 15 years, how would you describe it?

Most of students said that they are worried about the losing their privacy and increased techno-stress levels. Some of selected responses are:

- "New advances in genetics and neuroscience will lead to new understanding of brain."

- "In the future humans will benefit from nanorobots."

- "Nanotechnology will impact our lives by providing more options to work with."

- "Nanotechnology will allow production of defect-free products, thus improving the quality and life span of manufactured products."

- "Nanotechnology will take over the world!" 